\title{
4.6-billion-year-old aragonite and its implications for understanding the geological record of Ca-carbonate
}

\author{
Martin R. Lee ${ }^{1}$ Paula Lindgren ${ }^{1}$
}

Accepted: 14 July 2015/Published online: 13 August 2015

(C) The Author(s) 2015. This article is published with open access at Springerlink.com

\begin{abstract}
Owing to its diagenetic instability, aragonite is rare in the geological record and almost entirely absent from pre-carboniferous sedimentary rocks. The former presence of this mineral in older deposits has to be inferred from petrographic, chemical or isotopic proxies. Crystals of aragonite that formed around 4563 million years ago occur in carbonaceous chondrite meteorites, showing that under certain conditions, the orthorhombic polymorph of Ca-carbonate can survive essentially indefinitely. Together with other carbonate minerals, phyllosilicates and sulphides, this aragonite formed by low-temperature watermediated alteration of anhydrous minerals and glass in the interior of the meteorite's parent asteroid(s). The survival of aragonite for such a long time can be attributed to the loss of free water by its incorporation into phyllosilicates, and to the very low permeability of the fine-grained and organic-rich rock matrix that prevented the ingress of fresh solutions via intergranular flow. By analogy with these meteorites, terrestrial aragonite is likely to survive where it has been similarly isolated from liquid water, particularly in organic-rich mudrocks, and such deposits may provide important new evidence for deducing the original mineralogy of skeletal and non-skeletal carbonates in deep-time.
\end{abstract}

Keywords Aragonite $\cdot$ Carbonaceous chondrites $\cdot$ Marine mudrocks

Martin R. Lee

Martin.Lee@Glasgow.ac.uk

1 School of Geographical and Earth Sciences, Gregory Building, Lilybank Gardens, Glasgow G12 8QQ, UK

\section{Introduction}

Finding carbonate minerals in the geological record whose original crystal structure and composition have been preserved is crucial for understanding long-term changes to the Earth system including its climate and ocean chemistry. Correct determination of the mineralogy of biogenic carbonates is also important for tracking invertebrate evolution and studying taxonomic relationships. For example, secular variations in ocean chemistry have been identified through fluctuations between aragonite and calcite in the dominant mineralogy of inorganic marine carbonates (Sandberg 1975, 1983), and this record can be traced back 2700 million years (Hardie 1996, 2003; Ries et al. 2008). The relationships between the mineralogy and chemical composition of skeletal carbonates and seawater chemistry are considerably more complex owing to the biological control on mineralization and the operation of various evolutionary drivers (e.g., Kiessling et al. 2008; Zhuravlev and Wood 2008; Porter 2010). Using the calcium carbonate record to explore these and other processes in deep-time is challenging owing to the diagenetic instability of carbonate minerals in general, and aragonite in particular. Aragonite is scarce in Upper Palaeozoic sedimentary rocks (Wendt 1977), and there has been only one description of the mineral from Lower Palaeozoic deposits (Balthasar et al. 2011) and one from the Archaean (Lepot et al. 2008). The former presence of aragonite can only be inferred using proxies including the petrographic characteristics of replacive calcite and its chemical and isotopic compositions (e.g. Davies 1977; Mazzullo 1980).

The purpose of this short review is to draw attention to the oldest known aragonite, which occurs in carbonaceous chondrite meteorites and formed shortly after the birth of the Solar System. Although its occurrence in an 
extraterrestrial rock might imply that this aragonite is of limited use for understanding terrestrial carbonates, these meteorites are surprisingly similar in their properties to common lithologies on Earth. For example, the carbonaceous chondrites are comparable in grain size to mudrocks, and their original mineralogy and diagenetic history are analogous to that of basaltic volcanic ash. Furthermore, as the aragonite formed together with calcite and dolomite in an environment that was free of any biological influence, an understanding of the conditions under which it crystallised may suggest new directions for exploring inorganic carbonate precipitation on Earth.

\section{Carbonaceous chondrite meteorites}

The carbonaceous chondrites are pieces of small planetary bodies, principally asteroids and possibly also comets, which have remained largely unchanged since the birth of the Solar System (McSween 1979). Eight groups of carbonaceous chondrites have been recognised, and are distinguished on the basis of their mineralogy, petrography, and chemical and isotopic compositions. Each group is a sample of one or more asteroidal or cometary 'parent bodies'. The aragonite that is the subject of this review is most common in the CM group carbonaceous chondrites. The prefix ' $\mathrm{C}$ ' denotes carbonaceous, and the suffix 'M' represents Mighei, which is the type meteorite of the CM group. The name Mighei comes from the place in the Ukraine where the meteorite was recovered in 1889 (Graham et al. 1985). All of the carbonaceous chondrites used in this study are described as 'falls', which means that they were seen to land and collected shortly afterwards. Thus, none of these meteorites have had the opportunity to interact with terrestrial water, and so we can be confident that the aragonite is extraterrestrial in origin.

Most of the CM carbonaceous chondrites contain chondrules, which are objects up to a few millimetres in size that are composed mainly of ferromagnesian silicate minerals. Chondrules formed at high temperatures within the solar nebula along with grains of silicate, oxide and sulphide minerals, metal and glass. The oldest of these objects, which are called calcium- and aluminium-rich inclusions, have been dated to $4568.2+0.2 /-0.4 \mathrm{Ma}$ (Bouvier and Wadhwa 2010). The majority of the CM meteorites belong to petrologic type ' 2 '. This classification means that the chondrules lie within a fine-grained matrix that contains other 'high temperature' grains together with organic matter (up to $\sim 2 \mathrm{wt} \%$ ), and minerals including serpentines, sulphides and carbonates that formed by lowtemperature water-mediated alteration of the most reactive of the high-temperature constituents (e.g. Tomeoka and Buseck 1985; Zolensky et al. 1993; Sephton et al. 2003; Brearley 2006). The aqueous fluids responsible for alteration were generated by the melting of water ice, probably accompanying heating of the interior of the parent body by short-lived radioisotopes including ${ }^{26} \mathrm{Al}$ (e.g. Grimm and McSween 1989). Despite significant changes to their original mineralogy, the CM carbonaceous chondrites have largely retained their initial chemical compositions (McSween 1979). This apparent contradiction is explained by alteration having taken place in a chemically nearclosed system within which aqueous solutions were essentially static, probably owing to the very low permeability $\left(10^{-19}\right.$ to $\left.10^{-17} \mathrm{~m}^{2} ; 0.1-10 \mu \mathrm{D}\right)$ of the fine-grained matrix (Bland et al. 2009). This value of permeability is very similar to that of terrestrial mudrocks (Neuzil 1995).

\section{Carbonate minerals in the CM2 carbonaceous chondrites}

Carbonates constitute $<\sim 4$ vol\% of any one CM2 meteorite, and occur mainly in the fine-grained matrix. Four minerals have been identified: aragonite, breunnerite, low$\mathrm{Mg}$ calcite and calcian dolomite $\left(\mathrm{Ca}_{52-53} \mathrm{Mg}_{36-40} \mathrm{Mn}_{3-5}\right.$ $\mathrm{Fe}_{4-7}$ ) (de Leuw et al. 2010; Lee et al. 2014). These minerals occur as single crystals or polycrystalline grains that range in size from $\sim 5$ to $\sim 150 \mu \mathrm{m}$ (Johnston and Prinz 1993; de Leuw et al. 2010; Lee et al. 2012) (Fig. 1). Aragonite has been distinguished from calcite by electron diffraction in the transmission electron microscope, cathodoluminescence (CL) spectroscopy, electron backscatter diffraction and Raman spectroscopy (Müller et al. 1979; Barber 1981; Lee and Ellen 2008; Lee et al. 2013). Element mapping and CL imaging reveal that crystals of all four minerals are commonly zoned (Fig. 1d), and the pattern of zoning suggests that they grew as cements in water-filled pores (e.g., Lee and Ellen 2008; Lee et al. 2014). Clumped isotope thermometry shows that calcite formed at temperatures of between 20 and $71{ }^{\circ} \mathrm{C}$ (Guo and Eiler 2007), which is consistent with temperature ranges obtained from considerations of matrix mineralogy (Zolensky et al. 1989). Grains of calcite and dolomite have been radiometrically dated using the ${ }^{53} \mathrm{Mn}-{ }^{53} \mathrm{Cr}$ system $\left({ }^{53} \mathrm{Mn}\right.$ decays to ${ }^{53} \mathrm{Cr}$ with a half-life of $\left.3.7 \mathrm{Ma}\right)$, and results show that these minerals formed at $4563+0.4 /-0.5 \mathrm{Ma}$ (Fujiya et al. 2012), which is within $\sim 5 \mathrm{Ma}$ of the oldest objects in the Solar System (Bouvier and Wadhwa 2010). Thus, the carbonates are the products of a brief period of aqueous activity shortly after construction of their parent body by accretion within the solar nebula.

Aragonite crystals in the CM2 meteorites are commonly euhedral, and often elongate parallel to their $c$-axis (Fig. 1a). Some of them are enclosed within larger calcite grains, and the petrographic relationships between these two minerals show that the aragonite crystallised first 
Fig. 1 Images of aragonite (A) and calcite (C) in the finegrained matrix (M) of CM2 carbonaceous chondrites. a Backscattered electron SEM image of a euhedral crystal of aragonite from the Murray meteorite. b Backscattered electron SEM image of the Murchison meteorite showing a crystal of aragonite enclosed within calcite. The whitecoloured mineral surrounding the calcite is a hydrous sulphide. c Backscattered electron SEM image of a subhedral crystal of calcite in the Murray meteorite. d SEM-cathodoluminescence image of the same field of view as (c), showing that the calcite crystal is compositionally zoned
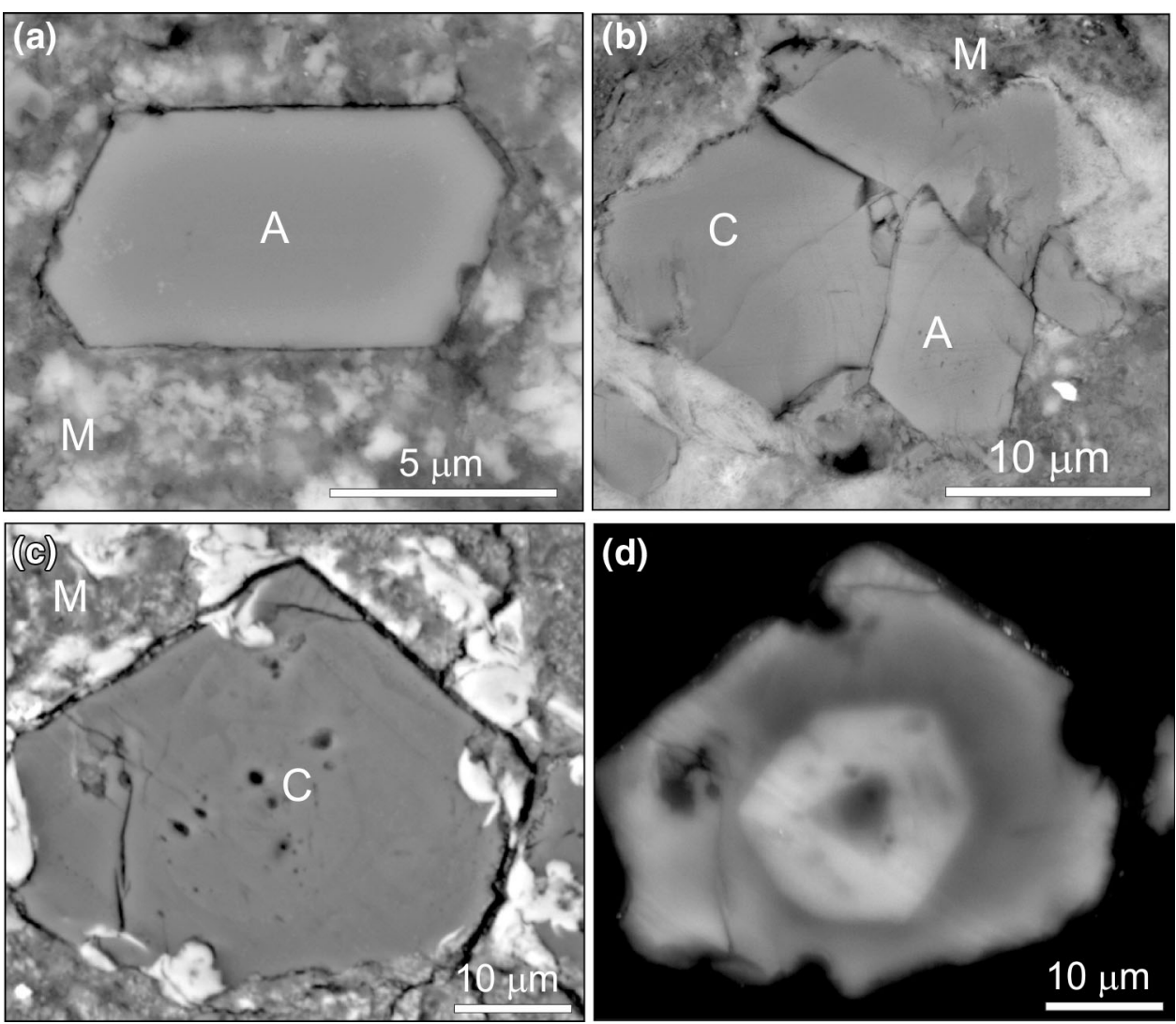

(Fig. 1b); similar calcite overgrowths on aragonite have been described from vadose meteoric cements in the Bahamas (Curran and White 1995). The principal control on the polymorph of calcium carbonate that precipitated from aqueous solutions within the parent body was their $\mathrm{Mg} / \mathrm{Ca}$ ratio. Specifically, those solutions in equilibrium with the aragonite had a $\mathrm{Mg} / \mathrm{Ca}$ ratio of greater than 1 , whereas solutions in equilibrium with calcite had a molar $\mathrm{Mg} / \mathrm{Ca}$ ratio of less than 1 (Lee and Ellen 2008; Lee et al. 2014). Thus, the principal control on Ca-carbonate polymorphism in the asteroidal/cometary parent bodies of the carbonaceous chondrite meteorites was the same as in terrestrial seawater (Hardie 1996).

\section{Implications for exploring the terrestrial Ca- carbonate record}

The presence of $\sim 4$.6-billion-year-old aragonite in the CM2 meteorites shows that despite the thermodynamic instability of this mineral at low temperatures and pressures (i.e. under the conditions prevailing in the interiors of asteroids and comets, and at shallow depths in the Earth's crust), under certain conditions, it can survive essentially indefinitely. There are two reasons for its preservation in the meteorite parent bodies: (i) liquid water was present only briefly because it was consumed by the hydration of ferromagnesian silicates, metals and glasses to form phyllosilicates; (ii) the asteroids had a very low intergranular permeability owing to their fine grain size and organic matter content, which prevented any liquid water that may have been present elsewhere within the parent body from coming in contact with the aragonite.

Our explanation for the preservation of extraterrestrial aragonite is consistent with the occurrences of aragonite in low-permeability Phanerozoic rocks on Earth (e.g. Wendt 1977; Sandberg and Hudson 1983). For example, preservation of mollusc shells (originally aragonite) in the Pennsylvanian Buckhorn Asphalt was facilitated by early diagenetic invasion by hydrocarbons, which greatly reduced permeability (Seuß et al. 2009). Hallam and O'Hara (1962) described aragonite in mollusc shells from the Scottish Mississippian, and suggested that their preservation was due to the fine grain size of their host organic-rich mudrocks. A similar explanation was proposed for sub-micrometre-sized aragonite crystals that were described from an Archaean (2724 Ma) stromatolite (Lepot et al. 2008). In this latter case, preservation was facilitated by enclosure of the aragonite in globules of carboxyl-rich organic compounds, and the permeability in the rock was limited by the presence of clay minerals within the stromatolite layers. 
Results from the meteorite record and from ancient terrestrial rocks together demonstrate that aragonite can be preserved essentially indefinitely where it is isolated from aqueous solutions by enclosure in a very low-permeability rock matrix. Thus, we predict that terrestrial marine mudrocks, especially those that are organic-rich, are likely to preserve the otherwise diagenetically unstable aragonite and high magnesium calcite. These rocks would therefore be attractive targets for future studies seeking to explore the evolution of the Earth system in deep-time.

Acknowledgments This work was funded by the UK Science and Technology Facilities Council through Grants ST/G001693/1 and ST/ K000942/1.

Open Access This article is distributed under the terms of the Creative Commons Attribution 4.0 International License (http://creative commons.org/licenses/by/4.0/), which permits unrestricted use, distribution, and reproduction in any medium, provided you give appropriate credit to the original author(s) and the source, provide a link to the Creative Commons license, and indicate if changes were made.

\section{References}

Balthasar U, Cusack M, Faryma L, Chung P, Holmer LE, Percival IG, Popov LE (2011) Relic aragonite from Ordovician-Silurian brachiopods: implications for evolution of calcification. Geology 39:967-970

Barber DJ (1981) Matrix phyllosilicates and associated minerals in C2M carbonaceous chondrites. Geochim Cosmochim Acta 45:945-970

Bland PA, Jackson MD, Coker RF, Cohen BA, Webber BW, Lee MR, Duffy CM, Chater RJ, Ardakani MG, McPhail DS, McComb DW, Benedix GK (2009) Why aqueous alteration in asteroids was isochemical: high porosity $\neq$ high permeability. Earth Planet Sci Lett 287:559-568

Bouvier A, Wadhwa M (2010) The age of the solar system redefined by the oldest $\mathrm{Pb}-\mathrm{Pb}$ age of a meteoritic inclusion. Nat Geosci 3:637-641

Brearley AJ (2006) The action of water. In: Lauretta DS, McSween HY Jr (eds) Meteorites and the early solar system II. The University of Arizona Press, Tuscon

Curran HA, White B (1995) Terrestrial and shallow marine geology of the Bahamas and Bermuda. Geological Society of America, Boulder

Davies GR (1977) Former magnesian calcite and aragonite submarine cements in upper Palaeozoic reefs of the Canadian Arctic: a summary. Geology 5:11-15

de Leuw S, Rubin AE, Schmidt AK, Wasson JT (2010) Carbonates in $\mathrm{CM}$ chondrites: complex formational histories and comparison to carbonates in CI chondrites. Meteor Planet Sci 45:513-530

Fujiya W, Sugiura N, Hotta H, Ichimura K, Sano Y (2012) Evidence for the late formation of hydrous asteroids from young meteoritic carbonates. Nat Commun 3:627

Graham AL, Bevan AWR, Hutchison R (1985) Catalogue of meteorites. British Museum (Natural History)

Grimm RE, McSween HY Jr (1989) Water and the thermal evolution of carbonaceous chondrite parent bodies. Icarus 82:244-280

Guo W, Eiler JM (2007) Temperatures of aqueous alteration and evidence for methane generation on the parent bodies of the $\mathrm{CM}$ chondrites. Geochim Cosmochim Acta 71:5565-5575
Hallam A, O'Hara MJ (1962) Aragonitic fossils in the lower carboniferous of Scotland. Nature 195:273-274

Hardie LA (1996) Secular variations in seawater chemistry: an explanation for the coupled secular variations in the mineralogies of marine limestones and potash evaporites over the past 600 m.y. Geology 24:279-283

Hardie LA (2003) Secular variations in Precambrian seawater chemistry and the timing of Precambrian aragonite seas and calcite seas. Geology 31:785-788

Johnston CA, Prinz M (1993) Carbonate compositions in CM and CI chondrites, and implications for aqueous alteration. Geochim Cosmochim Acta 57:2843-2852

Kiessling W, Aaberhan M, Villier L (2008) Phanerozoic trends in skeletal mineralogy driven by mass extinctions. Nat Geosci 1:527-530

Lee MR, Ellen R (2008) Aragonite in the Murray (CM2) carbonaceous chondrite: implications for parent body compaction and aqueous alteration. Meteorit Planet Sci 43:1219-1231

Lee MR, Lindgren P, Sofe M, Alexander CMO'D, Wang J (2012) Extended chronologies of aqueous alteration in the CM2 carbonaceous chondrites: evidence from carbonates in Queen Alexandra Range 93005. Geochim Cosmochim Acta 92:148-169

Lee MR, Sofe MR, Lindgren P, Starkey NA, Franchi IA (2013) The oxygen isotope evolution of parent body aqueous solutions as recorded by multiple carbonate generations in the Lonewolf Nunataks 94101 CM2 carbonaceous chondrite. Geochim Cosmochim Acta 121:452-466

Lee MR, Lindgren P, Sofe MR (2014) Aragonite, breunnerite, calcite and dolomite in the $\mathrm{CM}$ carbonaceous chondrites: high fidelity recorders of progressive parent body aqueous alteration. Geochim Cosmochim Acta 144:126-156

Lepot K, Banzerara K, Brown GE Jr, Philippot P (2008) Microbially influenced formation of 2,724-million-year-old stromatolites. Nat Geosci 1:118-121

Mazzullo SJ (1980) Calcite pseudospar replacive of marine acicular aragonite, and implications for aragonite cement diagenesis. J Sediment Petrol 50:409-422

McSween HY Jr (1979) Are carbonaceous chondrites primitive or processed? A review. Rev Geophys Space Phys 17:1059-1078

Müller WF, Kurat G, Kracher A (1979) Chemical and crystallographic study of cronstedtite in the matrix of the Cochabamba (CM2) carbonaceous chondrite. Tschermaks Miner Petrograph Mitt 26:293-304

Neuzil CE (1995) How permeable are clays and shales? Water Resour Res 30:145-150

Porter SM (2010) Calcite and aragonite seas and the de novo acquisition of carbonate skeletons. Geobiology 8:256-277

Ries JB, Anderson MA, Hill RT (2008) Seawater Mg/Ca controls polymorph mineralogy of microbial $\mathrm{CaCO}_{3}$ : a potential proxy of calcite-aragonite seas in Precambrian time. Geobiology 6:106-119

Sandberg PA (1975) New interpretations of Great Salt Lake ooids and of ancient non skeletal carbonate mineralogy. Sedimentology 22:497-573

Sandberg PA (1983) An oscillating trend in Phanerozoic nonskeletal carbonate mineralogy. Nature 305:19-22

Sandberg PA, Hudson JD (1983) Aragonite relic preservation in Jurassic calcite-replaced bivalves. Sedimentology 30:879-892

Sephton MA, Verchovsky AB, Bland PA, Gilmour I, Grady MM, Wright IP (2003) Investigating the variations in carbon and nitrogen isotopes in carbonaceous chondrites. Geochim Cosmochim Acta 67:2093-2108

Seuß B, Nützel A, Mapes RH, Yancey TE (2009) Facies and fauna of the Pennsylvanian Buckhorn Asphalt Quarry deposit: a review and new data on an important Palaeozoic fossil Lagerstätte with aragonite preservation. Facies 55:609-645 
Tomeoka K, Buseck PR (1985) Indicators of aqueous alteration in $\mathrm{CM}$ carbonaceous chondrites: microtextures of a layered mineral containing $\mathrm{Fe}, \mathrm{S}, \mathrm{O}$, and $\mathrm{Ni}$. Geochim Cosmochim Acta 49:2149-2163

Wendt J (1977) Aragonite in Permian reefs. Nature 267:335-337

Zhuravlev AY, Wood RA (2008) Eve of biomineralization: controls on skeletal mineralogy. Geology 36:923-926
Zolensky ME, Bourcier WL, Gooding JL (1989) Aqueous alteration on the hydrous asteroids: results of EQ3/6 computer simulations. Icarus 78:411-425

Zolensky ME, Barrett R, Browning L (1993) Mineralogy and composition of matrix and chondrule rims in carbonaceous chondrites. Geochim Cosmochim Acta 57:3123-3148 